\title{
Analysis of Corporate Culture and Enterprise Management Model
}

\author{
Ying Liu \\ Guangdong College of Business and Technology, Zhaoqing, Guangdong, 526020
}

Keywords: Enterprise Management, Enterprise Culture, Research Model

\begin{abstract}
With the continuous development of the times, the management mode of enterprises is constantly innovating. Nowadays, corporate culture has become the focus of people's attention. Corporate culture can reflect the core values of enterprises, and based on corporate culture, it can promote the exploration of management models, improve the effectiveness of business management and promote comprehensive management. This paper analyzes the relationship between corporate culture and corporate management by analyzing the corporate culture model with corporate culture as the core, and analyzes the limitations of corporate culture management model. Based on the limitations, it proposes a corporate culture model with corporate culture as the core.
\end{abstract}

\section{Introduction}

Corporate culture plays a guiding role in all aspects of enterprise development and plays an important role in the development of enterprises. The connotation of corporate culture is also extremely rich, including not only the various systems of enterprises, but also the spirit of enterprises. Environment, etc., corporate culture is an important branch of social culture, and also plays a more important role in national culture. Enterprise management can promote the development of enterprises and make the development of enterprises follow a certain direction. Enterprises can improve the production and management activities of enterprises through the formulation of corporate culture, regulate the organization, promote the management of enterprises through corporate culture, and realize the enterprise's development of.

\section{The connotation of corporate culture}

Corporate culture refers to the common understanding and basic beliefs of the enterprise itself that is recognized, shared and shared by all members of the organization within the organization for the need to deal with and solve problems for their own survival and development. Culture itself represents a civilized process, with the characteristics of the enterprise, is a process of formation of corporate civilization and corporate thought, which embodies a core idea and management idea of an enterprise, as well as its internal behavior and activities. . Enterprise culture is a corporate culture image unique to an enterprise, such as its value, belief, way of doing things and attitude. The thought and connotation of corporate culture can also be roughly divided into three levels: the most superficial layer reflects the material culture of the enterprise, which is embodied in the daily work behavior and ideological atmosphere within the enterprise, such as the production process, work details and customs of the enterprise. The second layer is embodied in the company's system and code of conduct formed by the long-term operation of the enterprise, and the rules and regulations for the compliance of all enterprise personnel. This is the ideological guidance and the normative behavior. It is Gaoyi. The corporate culture of the hierarchy; the third layer refers to the spirit and core ideas of the enterprise. It is the crystallization of corporate wisdom. The guiding ideology of all corporate culture and corporate behavior is the most important spiritual power of an enterprise.

Corporate culture has a distinct era. In order to adapt to the development and needs of the economy, enterprises will constantly change their methods and methods. Similarly, corporate culture is also in sync with the development of the enterprise, constantly changing and advancing with the times. It is the accumulation and performance of a specific historical period. Each of the different development stages will form a unique cultural brand of the enterprise, and will continue 
to evolve as time goes by, and gradually accumulate into the historical culture of the enterprise, thus forming a historical corporate culture. The goal of corporate culture is consistent with the goal of business management. It is to achieve the improvement of enterprise work efficiency and comprehensive benefits through better management, to maximize corporate benefits and minimize costs. Corporate culture and corporate goals for the strengthening of all aspects of the company's capabilities, the pursuit of corporate survival and development has always maintained a unified pace, the performance of the two aspects of the pursuit of ideas and forms. Another obvious feature of corporate culture is the personality of corporate culture. Every enterprise has its own corporate culture that is not equal. It is a collection of ideas that the company gradually formed in its own development process. The goals of the enterprise may be the same, but the specific corporate culture must be different. Each corporate culture is in itself. The accumulation of the struggle and development process has a unique corporate culture formed by the company itself.

\section{The promotion of corporate culture to business management}

Corporate culture, as the core of a company's core, has a strong impact on the overall working atmosphere and atmosphere of the company. Corporate culture can set a specific goal, require internal employees to form a common goal, unite the internal personnel of the enterprise, play the role of a glue, and form a unity within the enterprise through its own spiritual cohesive force. Positive and upward force. Such a company with a strong heart will be more efficient with less effort and easier to manage. The corporate culture that comes from the spirit of the soul has a huge role in promoting corporate management.

Corporate culture is the core idea of enterprise development. It is the crystallization of many years of experience and wisdom of enterprise members. It has important guiding role for the development strategy and development direction of enterprises. The strategic guidance of corporate culture on the direction of enterprise development, as well as the planning and forecasting of the development trend of the enterprise, make the enterprise clearer and better decision-making in the process of business management, and the management plans and means become clearer and more With a clear direction, we can work hard in one direction, avoiding detours and making wrong decisions. The company's own management capabilities have been enhanced, and corporate culture has contributed to it.

Corporate culture is an internal and orderly behavioral awareness standard that is formed consciously within the enterprise. This reflects the binding ability of corporate culture. The normative requirements of corporate culture on the thinking and behavior of employees within the enterprise will make the management of the enterprise more standardized and efficient, and the enforcement of rules and regulations within the enterprise will be stronger, which will help the realization of management effects. A good corporate culture has certain requirements for the quality and working attitude of the internal personnel. The realization of this implementation effect is actually the scope of business management. The constraint of corporate culture on the internal ideological behavior is precisely to promote the management of corporate management. The important power of the realization.

Corporate culture represents advanced and progressive work thoughts and attitudes. It has a strong humanity and is very concerned with the personal cultivation and working attitude of the insiders. It is a kind of spiritual support. Through its strong spiritual strength, corporate culture inspires and supports employees with positive and advanced thinking and work ability, pays more attention to the realization of employees' self-worth, and gives employees an energetic spirit within the company, forming a positive inside the company. Strength, let the employees inside the company have a strong sense of mission and a sense of honor. A positive trend is an indispensable condition for an enterprise. It has contributed to the success of business management to a large extent, and it also reflects the stimulating effect of the entrepreneurial spirit of enterprise culture on corporate management behavior. 


\section{Method of effective integration of corporate culture and enterprise management}

How to effectively integrate corporate culture and enterprise management, so that Chinese enterprises have their own most suitable and most successful enterprise management model. I believe that first of all, we must strengthen the understanding of corporate culture of corporate managers in China, only the managers of enterprises They clearly understand the corporate culture, understand what the core of corporate culture is, and understand that only with a good corporate culture, and the implementation of this cultural value into management can make the company develop a lot, enterprise management Only then will they attach importance to corporate culture.

If we want to effectively integrate corporate culture with the enterprise management model, we must form a management mechanism that is conducive to the creation of corporate culture, and create an atmosphere conducive to the creation of corporate culture, so as to cultivate employees' corporate values and enable employees to recognize their own businesses. Culture. At the same time, it is necessary to form an evaluation mechanism for corporate culture and strengthen the institutional construction of enterprises. It is a long-term task to form the corporate culture that is most suitable for the company. Because the corporate culture is not immediately formed, it requires a very long process. Therefore, it is necessary to strengthen the institutional construction of the enterprise and consolidate the existing ones. At the same time of excellent corporate culture, we must form a new corporate culture with the development of the company.

Considering that China's economic level still has a certain distance from developed countries, there is still no perfect system management model theory. Therefore, we need to learn the management model of many excellent foreign companies and use our good business. Go in management. However, after all, our company's business environment is different from that of foreign companies. Our company is grown in a country with a long history and cultural heritage. We have our own unique local culture. Therefore, when learning from foreign companies, we must pay attention to it. Incorporate our excellent characteristic culture into the management of the company and form our own characteristic corporate culture. Corporate culture is like a national culture. It is a kind of value and a spiritual pillar. Enterprise management is such a value. The good carrier of this spiritual pillar, the integration of corporate culture and corporate management is to let a company own So, only in this way, companies can revitalize. Although there are still some problems in the development of China's enterprises, many enterprise managers have applied the excellent foreign enterprise management models to their own enterprise management, and there have been a number of international companies with excellent corporate culture. Large company. This kind of successful experience also reveals a message: eclecticism and innovation. I believe that future business management competition will be a cultural competition.

In the enterprise, pay attention to the construction of corporate culture, but we must not neglect the construction of the internal system of the enterprise. The fundamental purpose of the construction of corporate culture is to improve the management level of the enterprise, so that the production within the enterprise can be developed benign, and the internal management mechanism of the enterprise can mutually The supplements play a mutually reinforcing role. Enterprises are an important part of the market economy. If enterprises want to gain benefits in fierce competition, they should improve their internal systems. Therefore, enterprises should take the principle of innovation and establish a sound system so that the system can make the enterprise more dynamic and enable the enterprise to generate internal motivation. In the construction of corporate culture, enterprises should form a platform of fairness and integrity so that employees can compete fairly. The various laws and regulations of the enterprise also have a certain guiding effect on the development of corporate culture, and can make the development of corporate culture move toward the direction of individualized development, realize the diversity of corporate culture, and therefore lead to a larger corporate culture. The reason for the difference lies in the various systems within the enterprise. The enterprise system is an important embodiment of the corporate culture. The enterprise system guides the employees' behavior, the corporate culture is improved through the enterprise system, and the enterprise system also needs the corporate culture. 


\section{Conclusion}

The relationship between corporate culture and corporate management is mutually reinforcing and mutually reinforcing. Corporate culture has an extraordinary significance for the improvement of corporate management capabilities. The construction and development of corporate culture is also part of the management of the enterprise. Therefore, strengthening corporate culture construction is one of the important means to promote the strengthening of corporate management capabilities. Promoting the enhancement of corporate management through the construction of corporate culture is a very wise and multi-pronged initiative.

\section{References}

[1] Huang Jiabin. The principle and mode selection of the integration of the corporate culture of the joint venture [J]. China Stone, 2010, (3).

[2] Luo Xianchu. Culture wins dignity for business [J]. Chinese and foreign corporate culture, 2010, (5).

[3] Sun Xuya, Mei Qiang. A review of the literature on the impact of corporate culture on human resource management [J]. China Business, 2010, (10).

[4] Wang Qiang. The important role of enterprise culture construction in enterprise management [J]. Value Engineering, 2010, (3).

[5] Jiang Shuhua. Talking about the choice of ways to reorganize corporate culture integration [J]. Metallurgical Management, 2010, (5) 